\title{
Moderating Effect of Playfulness on the Correlation between Optimism and Creativity of New Immigrant Schoolchildren in Taiwan
}

\author{
Cheng-Ping Chang1, Chun-Chieh Tseng'2, Hsin-Hao Chen ${ }^{3}$, Tsai-Chih Hsieh 1,4* \\ ${ }^{1}$ Department of Education, National University of Tainan, Taiwan \\ ${ }^{2}$ Department of Sport Health and Leisure, Chung Hwa University of Medical Technology, Taiwan \\ ${ }^{3}$ Graduate Institute of Education Leadership and Evaluation, Southern Taiwan University of Science and Technology, Taiwan \\ ${ }^{4}$ Department of Hotel Management, Tainan University of Technology, Taiwan \\ E-mail: justin23@mail.nutn.edu.tw, elekwem@yahoo.com.tw, yuching8892@gmail.com, *tsaichihhsieh@gmail.com
}

How to cite this paper: Chang, C.-P., Tseng, C.-C., Chen, H.-H., \& Hsieh, T.-C. (2020). Moderating Effect of Playfulness on the Correlation between Optimism and Creativity of New Immigrant Schoolchildren in Taiwan. Creative Education, 11, 1357-1374.

https://doi.org/10.4236/ce.2020.118100

Received: July 22, 2020

Accepted: August 16, 2020

Published: August 19, 2020

Copyright $\odot 2020$ by author(s) and Scientific Research Publishing Inc. This work is licensed under the Creative Commons Attribution International License (CC BY 4.0).

http://creativecommons.org/licenses/by/4.0/

\begin{abstract}
This study recruited 483 new immigrant children in the fifth and sixth grades of elementary schools in Tainan to determine the correlation between various aspects of their optimism and creativity and the moderating effect of playfulness. Statistical methods involving items, reliability, analysis, descriptive statistics, two-way analysis of variance, and the moderating effect test were applied to questionnaire data. Significant positive relationships between optimism, playfulness, and creativity were identified with the schoolchildren, and playfulness moderated the relationship between their optimism and creativity.
\end{abstract}

\section{Keywords}

New Immigrant Schoolchildren, Optimism, Creativity, Playfulness

\section{Research Background}

Due to demographic changes induced by global mobility and social transformations caused by globalization and multiculturalism, Taiwan faces the problem of an aging population as it undergoes other changes in the social and economic environment, the most noteworthy of which may be the increasing number of new immigrant children. Marriages across countries have become an unstoppable trend in Taiwan, and their influence on Taiwan society should not be underestimated. According to statistics compiled by the Ministry of the Interior in 2018, more than 650,000 immigrants (more than $3 \&$ of Taiwan's population) had acquired ROC nationality and an identity card, outnumbering the indigenous population $(560,000)$ in 2018 and constituting the second largest group in 
Taiwan.

This study tracked the population of immigrant children to gain more understanding of the subject. According to a survey conducted by the Department of Statistics of the Ministry of Education, the number of Taiwanese elementary schoolchildren decreased from $1,754,095$ in 2007 to $1,146,679$ in 2017, and the percentage of immigrant students increased from $3.83 \%(103,587)$ to $10.07 \%$ $(181,301)$ during the decade. New immigrant schoolchildren now comprise 9.37\% of all elementary schoolchildren in Taiwan.

An unprecedented experience for modern Taiwan, the influx of immigrants requires more attention to be paid to education for immigrant children, which is a non-negligible challenge affecting Taiwan's population and educational competitiveness. In recent years, research and education topics regarding immigrant children have mostly focused on helping them adapt to the local culture and enhancing their learning outcomes; few studies have explored their advantages in developmental and the gifts they are born with. The increased enrollment of immigrant children in schools elucidates the fact that these students will become part of Taiwanese society in the foreseeable future and will affect the overall quality of population and national competitiveness. Competent education authorities have noted the profound effect of problems regarding education on immigrant children and the necessity of problem identification and formulation of relevant strategies.

The advance in information technology has ushered in an era of artificial intelligence and information revolution. The rapid development of technology has subjected Taiwan's economic development to entirely new challenges. To enhance national competitiveness, governments around the world have placed a high value on innovation, creativity, and other elements they deem essential in this wave of development. According to the most recent Global Competitiveness Report 2019 published by the World Economic Forum, Taiwan, ranked fourth worldwide in innovation capability, received a much higher score than other countries in the category and was described as a "super innovator" along with Germany, the United States, and Switzerland. The renowned British historian Arnold J. Toynbee stated that creativity plays a crucial role in improving human civilization and quality of life, and real creative activities deliver valuable results to human society. Countries without creative power will fail to overcome future challenges, nor can they adapt to changes in a new generation. Michael Porter, a strategic management expert in the United States, assessed a country's competitiveness in 10 successful industries and concluded "continuous innovation" is the key factor to success. Furthermore, he pointed out that an innovative mechanism that enables continuous progress is the key to forming national competitive advantages. Sternberg (2001) asserted that a wise person should have both intelligence and creativity. Shen (2005) noted that national competitiveness can be enhanced through creativity. Former Microsoft president Bill Gates once stated that the most important factors for a person to achieve success in modern times are creativity and perseverance. Accordingly, creativity is closely related to 
the improvement of national competitiveness, updating and development of technologies in advantageous industries, and organizational reforms and innovations in response to sociocultural changes and future global developments.

Because countries around the world stress the importance of creativity, numerous studies have pursued methods and impact factors that enhance human creativity. Through a comprehensive analysis, the authors identified a large amount of relevant Taiwanese and international literature focusing on the characteristics, motivations, attitudes, and abilities of individuals, as well as the interaction between individuals and the environment, that influence creativity (Marzano, 2005/2007; Hunter, Bedell, \& Mumford, 2007; Simonton, 2009; Runco, 2007). Amabile (1988) and Oldham and Cummings (1996) claimed that personality traits affect the development of individual creativity, and this theory attracted the interest and attention of researchers. Supporting and extending the idea, the field of psychology has advocated the power of positivity, which is providing new research directions. In his book Authentic Happiness, the "positive psychologist" Seligman noted that existing studies on psychology have mostly centered on psychological illnesses and rarely discussed happiness and life meaning. (The authors discovered that early psychological research focused on topics such as stress, diligence, positivity, performance, depression, and negative emotions.) The emergence and broad development of positive psychology have prompted many researchers to adopt a new approach and explore positive personality traits, which yield/numerous critical findings and conclusions. Aligning with the trend in psychology and current research directions and foci, the present study explored topics and applications derived from optimism, playfulness, and creativity in an attempt to yield new findings and developments. According to statistics compiled by EBSCOhost database, approximately 90 studies published between 2000 and 2018 in major journals were about optimism. ProQuest Digital Dissertations Database reported approximately 2298 studies on optimism published during 2000-2018. Optimism has been widely discussed outside Taiwan over the past 20 years. By contrast, relevant Taiwan journals and dissertation materials are relatively lacking, in turn motivating this study.

Research on playfulness has switched its focus from child playfulness to the development and application of theories of adult playfulness. This has benefited many companies and organizations by enabling them to resolve problems and strengthen performance. Well-known examples include Google and 3M, both of which argue that play and relaxation can stimulate creativity. The two companies put this realization into practice and let their employees enjoy $20 \%-30 \%$ "free time" at work. Although the scope and subject of relevant research have extended to enterprises, adults, schools, and teachers, this study was the first to explore the playfulness and creativity of new immigrant schoolchildren and to develop assessment indicators.

Based on the discussed research background and motivation, our research objectives were as follows: 1) to explore the status of optimism, playfulness, and 
creativity in immigrant schoolchildren in Tainan; 2) to understand the connection between optimism, playfulness, and creativity of the new immigrant schoolchildren; and 3) to explore the moderating effect of new immigrant school children's playfulness on the relationship between their optimism and creativity.

\section{Literature Review}

\subsection{Creativity}

Guilford, a forerunner in research on creativity, emphasized the importance of creativity research at the American Psychological Association convention in 1950, calling people's attention to the subject (Amabile, 1996). Guilford (1965) deemed creativity, characterized by fluency, flexibility, and originality, a cognitive ability to engage in divergent thinking. In Webster's Dictionary, "creativity" carries meanings of "make out of nothing" and "for the first time." Nonetheless, researchers often define creativity differently according to their research interests or orientations. Williams (1972) defined creativity using cognitive (fluency, flexibility, originality, and refinement) and affective (curiosity, adventure, challenge, and imagination) factors. Amabile (1983) suggested that creativity is a response or product of task evaluated by experts as creative; such a product is the result of interaction among domain-relevant skills, creativity-related skills, and task motivation. Sikszentmihalyi (1990) defined creativity as the result of interaction of individuals, domains, and disciplines. According to Zhou and George (2001), creativity is the creation of new and useful ideas by individuals expressed through opinions and actions. Sternberg (2003) proposed that creativity comprises abilities such as exploration, imagination, hypothesis, synthesis, and invention. Creativity, ubiquitous in life, is found, more or less, in all individuals (Williams, 2002). In brief, a confluence of approaches to creativity has changed the orientation of creativity research from an initially single-dimensional to a multidimensional one.

Many theories and studies have discussed creativity, and they have varied by focus and orientation. For example, studies based on psychoanalytic theory emphasize the subconscious mind and superego; research centering on behaviorism advocates that complex behaviors are derived from learning and emphasizes that environmental stimuli promote creativity; studies based on humanistic theories stress the importance of self-actualization; historiometric-oriented research analyzes data in historical documents to identify common traits of individuals known for their creativity and inventiveness (Chuang, 2012; Chang, 2007; Simonton, 1988). Despite competing theories such as the componential model of creativity by Amabile (1983), the triangular theory of creativity proposed by Sternberg in 1988, the investment theory of creativity (Sternberg \& Lubart, 1995), the systems theory of creativity (Csikszentmihalyi, 1996), and components of group creativity (Siau, 1995), many researchers have inclined toward the use of a confluence approach to understanding creativity. Employing a multidimensional framework, this study also adopted a confluence approach as its theoretical basis. 


\subsection{Playfulness}

Lieberman (1965) was the first scholar to define playfulness as a player's personality, which aroused interest in the subject and prompted subsequent research. Csikszentmihalyi (1975) suggested that people with a playful predisposition are driven by intrinsic motivation to advance toward a set goal or assign meaning to things or behaviors. Unbound by externally established rules, people with a playful predisposition display active commitment. Aguilar (1985) interpreted playfulness from the perspective of the social situation and believed that playfulness is a predisposition individual is born with, and social environments stimulate the development and demonstration of playfulness. Because individual playfulness is affected by social elements, a demonstration of individual playfulness is the result of the interaction between personal traits and external environmental factors. Aguilar combined the arguments of trait and situational theories to propose the interaction theory of playfulness. Webster (1989) regarded playfulness as a spontaneous attitude that affects a player's dominance, control, satisfaction, and joy. Barnett (2007) defined playfulness as a means of framing a situation that presents an individual amusement, humor, and entertainment. Yu (2005) determined that a high level of perceived playfulness enables individuals to spontaneously concentrate and make a deep commitment while feeling satisfied with themselves and enjoying the moment. In addition to relaxation and pleasure, perceived playfulness entails stress relief, mood changes, freedom, innocence, and humor, all of which contribute to creative inspiration and unexpected favorable performance. Playfulness, a potential quality in games, is the expression of an intrinsic motivation for natural pleasure, freedom, lightheartedness, and joy. Playfulness is process-oriented, guided by the organism-dominated question of "What can I do with this object," related to intangible instrumental behaviors, and associated with active engagement. Multidimensional, playfulness is the combination of factors of cognition, affection, and behaviors (Wang). Playfulness, then, can be described as a demonstration of spontaneity, imagination, emotion, fun, and an enjoy-the-moment attitude, for example at work or in the classroom. Characterized by its changes with the external environment, playfulness has six features: 1) taking pleasure in it; 2) finding joy in creating things and solving problems; 3 ) relaxing physically and mentally to enjoy oneself; 4) remaining humorous to enjoy oneself; 5) being a child at heart to enjoy the fun; and 6) staying engaged and actively completing a task.

\subsection{Optimism}

The Oxford English Dictionary defines "optimism" as a feeling that good things will happen, the tendency to look at the bright side of things, and having confidence in success. Research on optimism began in the mid-1980s, and Carver and Scheier, recognized for their early studies of optimism, asserted that optimistic people expect good things to happen to them (1985). Subsequently, scholars defined optimism from different perspectives. Segerstrom (2001) deemed that op- 
timistic people expect positive outcomes regardless of the general state or of special circumstances. Western scholar Cabell claimed that we live in the best of all possible worlds.

Optimism is a frequently mentioned positive personality trait. Carver and Scheier (2003) held that optimism refers to an individual's stable tendency to expect positive outcomes when facing unknown life events and discovered that optimists usually make positive predictions concerning unknown life events. Researchers propose different perspectives toward optimistic traits. Some regard optimism as a cognitive bias or a positive hallucination that underestimates negative results and overestimates positive results (Dember, Martin, Hummer, Howe, \& Melton, 1989; Taylor \& Armor, 1996). Relying on social cognitive theory, Bandura (1986) posited that assessments of individual cognition, self-efficacy, and outcome expectations are responses to specific situations and are not determined by personality or traits. According to this understanding, individuals may feel optimistic toward certain aspects of life, such as work or making friends. Attribution theory regards optimism as individuals' interpretation of positive events that occur (Peterson \& De Alila, 1995; Seligman, 1991). Schwarzer (1994) considered optimism generalized self-efficacy-optimistic individuals have high degrees of confidence in their ability to overcome external environment changes. Snyder (2002) defined optimism as accepting present difficulties with rational, positive emotions and attitudes. The self-regulation theory proposed by Scheier and Carver (1985) described optimism as a tendency to expect positive outcomes, a construct which has frequently been applied in recent years. Later, Scheier and Carver (2003) applied an expectancy-value theory of motivation as the basis for optimism and to explain how human experience is affected. This was integrated with self-regulation theory to address the formation of behaviors and operation of optimism. Finally, catastrophe theory has been applied to explain the mentality of optimists.

\subsection{Relationship between Variables and Deduction of Hypotheses}

The research uncovered that optimistic people have greater flexibility and a more open experience in developing creativity than do pessimistic people. Chang and Farrehi (2001) demonstrated that optimism is significantly correlated with creative thoughts. In addition, Amabile (1988) and Luthans et al. (2007) discovered in their research on teamwork that when members are in an optimistic state, they stimulate more ideas and generate more creative behaviors. These phenomena have indirectly confirmed that optimism positively affects creativity. Accordingly, this study proposed the following hypothesis:

H1: A significant and positive relationship exists between optimism and creativity among new immigrant schoolchildren in Tainan.

Playfulness has also been identified by multiple studies as a factor that positively correlates with creativity. Webster researched playfulness as early as 1953 and was followed by scholars such as Lieberman and Barnett who investigated 
children's play behaviors, initiating the subsequent research on child playfulness and learning outcomes. Glynn and Webster (1992) found in their research that playfulness is a stable personality trait. Glynn and Webster studied 300 adults in different regions of the United States and identified a positive correlation between playfulness and creativity. Csikszentmihalyi (1999) interviewed 91 successful people from different industries and considered most of them creative. Through the interviews, Csikszentmihalyi learned that "designing or inventing new things" interested these successful people the most, and that successful people were motivated to engage in what they deemed "fun." They spent considerable time weekly in recreation for fluent experiences of creativity. Maintaining a playful attitude enables successful people to enjoy a work process. Lo's (2012) research specifically concluded that playing is a natural instinct of human beings that enhances creativity. Barnett (1991), Glynn and Webster (1992), and Dansky (1999) all suggested that playfulness improves individual learning and creativity. These findings have been supported by Taiwanese and international research on playfulness and creativity; thus, this study proposed the following hypothesis:

H2: A significant and positive relationship exists between playfulness and creativity among new immigrant schoolchildren in Tainan.

Professor Amabile of Harvard University, known for her research on creativity, interviewed 120 scientists from various companies in 1988 and identified 10 personality traits beneficial to creative problem-solving. Many of the traits were related to positivity and optimism, which enabled her to infer a connection between optimism and creativity. By identifying this connection, Amabile encouraged research on it, and it helped motivate this study. Accordingly, the study proposed a hypothesis as follows:

H3: Playfulness of new immigrant schoolchildren in Tainan moderates the relationship between their optimism and creativity.

\section{Methods}

\subsection{Research Framework}

Focusing on new immigrant schoolchildren in Tainan City, this study explored the correlation between optimism and creativity, the correlation between playfulness and creativity, and the moderating effect of playfulness on the relationship between optimism and creativity. To offer an overall view of this study, a schematic of the research framework is provided by Figure 1, wherein the research variables are detailed and possible correlations between them presented.

\subsection{Research Participants and the Sampling Method}

Tainan is one of six special municipalities in Taiwan. Since 2014, an administrative focus in Tainan has been on the creative industry to enhance cultural creativity. Lin (2012) argued that elementary schoolchildren are at a stage of learning new fields of knowledge and have unlimited creative potential. Studies have 


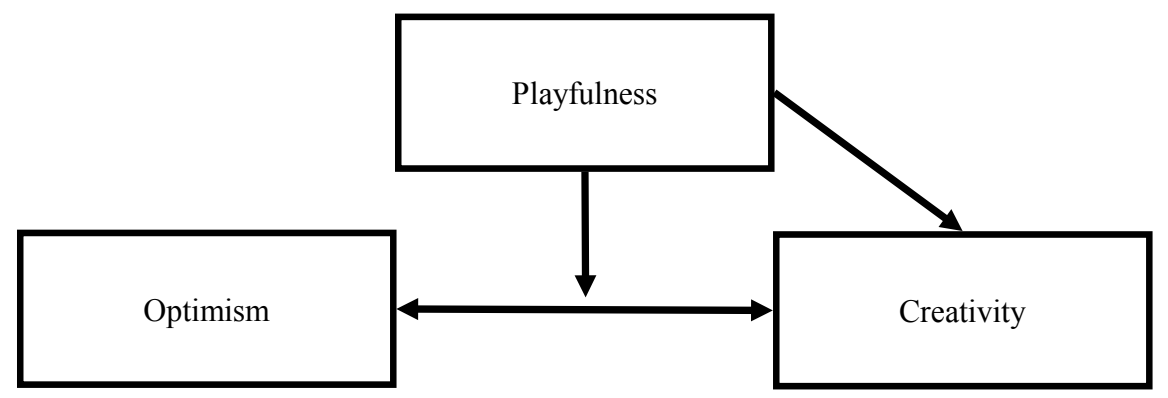

Figure 1. Schematic of the research framework.

revealed that the upper (fifth and sixth) grades of elementary school are a vital educational stage for schoolchildren to develop creativity (Chen, 2008; Cheng \& Tsai, 2012) and constitute a critical period for inspiring creativity. Tainan was selected as the research setting, and fifth- and sixth-grade immigrant schoolchildren in the city were surveyed. In 2018, the number of new immigrant children in the fifth and sixth grades in the city was 1373 and 1690, respectively. Each of these children came from a family where at least one parent was an immigrant from China, Vietnam, Indonesia, Thailand, the Philippines, Cambodia, Japan, Malaysia, the United States, South Korea, Myanmar, Singapore, Canada, or elsewhere.

A pretest questionnaire was designed, the validity of which was assessed by experts in pretest questionnaire development. Six upper grade classes (two each from three elementary schools) were randomly selected to pretest the instrument. According to the sampling principles of $\mathrm{Wu}$ and $\mathrm{Tu}$ (2010), the number of pretest participants should be $3-5$ times the number required by the subscale with the most items. The questionnaire collected data in a census manner and new immigrant schoolchildren were identified from their responses to demographic items.

\subsection{Research Instruments}

A questionnaire comprising scales for optimism, playfulness, and creativity was designed. The research instruments adopted included demographic data of respondents, scales serving as references for the questionnaire, and measurement method, dimensions, and items. The demographic data were sex, age, parental nationality, parental income, parental educational attainment, and school district, and the information collected was used in subsequent analysis. For optimism, the Revised Life Orientation Test (Scheier \& Carver, 1985) translated into Chinese and revised was used. The scale comprises six items, three of which are positive and three negatives. The negative items were reverse-scored, and all items were totalled; a higher score reflected greater optimism. For the Children Playfulness Scale regarding its reliability, the Cronbach's $\alpha$ of the overall scale and subscales (Stay Curious \& Try New Things, Interact with People \& Exhibit Humor and Pleasure, Make Full Commitment, and Enjoy the Moment) were $.82, .71, .71$, and .65 , respectively. The variation explained by each factor 
was $30.68 \%, 8.68 \%$, and $3.84 \%$, respectively, amounting to a total of $43.2 \%$. Presently, scales for measuring the playfulness of elementary schoolchildren are lacking in Taiwan, especially those targeting new immigrant schoolchildren. The creativity scales of Lin and Wang (1994) and other relevant measurements were revised to develop a scale targeting schoolchildren's creativity. The scale comprised two dimensions, namely creative ability and creative tendency. The three scales were self-reported, and respondents were asked to respond on a 5-point Likert scale (1-strongly disagree, 2-disagree, 3-neither agree or disagree, 4-agree, and 5-strongly agree). A high score on a scale indicated a high level of self-perceived optimism, playfulness, or creativity.

\subsection{Statistical Methods for Data Processing}

SPSS version 22.0 was used to analyze the questionnaire data. According to the research objectives and the requirements of each hypothesis, statistical methods concerning items, reliability, analysis, descriptive statistics, two-way analysis of variance (ANOVA), and moderating effect were adopted to analyze the data.

\section{Results and Analysis}

\subsection{Item Analysis}

This study explored the optimism, playfulness, and creativity of upper grade new immigrant elementary schoolchildren in Tainan. In the pretest stage of scale development, we first identified the extremely high and low groups for each variable then compared the differences between the groups using the $t$-test to determine the discriminatory power of items. The $t$ values of the variables indicated high statistical significance $\left(p<.001^{\star * *}\right)$ and, thus, the items had high discriminatory power.

After we finalized the questionnaire, the survey was conducted, with a total of 770 valid questionnaires returned, 483 of which were selected. Of the respondents, male schoolchildren $(249 ; 51.6 \%)$ outnumbered female schoolchildren $(234 ; 48.4 \%)$. More respondents were in the sixth $(421 ; 54.7 \%)$ than the fifth $(349 ; 45.3 \%)$ grade. The fathers of the respondents were mostly Taiwanese (453; 93.8\%), followed by those from China, Malaysia, Thailand, the Philippines, and other countries $(50 ; 3.9 \%)$. The majority of immigrant mothers were from China (252; 52.4\%), followed by those from Vietnam (162; 33.5\%); 69 (14.2\%) were from Taiwan, Malaysia, Indonesia, Thailand, the Philippines, or elsewhere. Regarding the educational attainment of respondents' fathers, the largest group was those with a senior high school diploma $(212 ; 43.9 \%)$, followed by those with a college degree $(145 ; 30.0 \%)$ or a junior high school education $(80 ; 16.6 \%)$; those with a master's degree (30) or elementary school education (16) together accounted for only $9.7 \%$ of the fathers. Among the respondents' mothers, the largest group was those with a senior high school diploma $(176 ; 36.4 \%)$, followed by those with a junior high school education $(117 ; 24.2 \%)$ or a college degree $(90$; $18.6 \%)$; those with a master's degree (40) or elementary school education (60) 
accounted for $18.7 \%$ of the sample.

Factor analysis results revealed that all variables yielded a Kaiser-Meyer-Olkin value of greater than .7 and high significance in the Bartlett sphere test, which indicated a good fit. A cumulative explained variation of greater than $50 \%$ implied that the scales have good convergent validity. In the two-way ANOVA, both optimism and playfulness reached high significance in creativity. The highly significant interaction between optimism and playfulness rendered the context between variables worthy of exploration (Table 1 ).

\subsection{Correlation Analysis}

Pearson product-moment correlation coefficients were calculated to determine the correlation between variables. Tables 2-5 reveal highly significant positive correlations between the variables and dimensions of optimism, playfulness, and creativity, with the highest correlation identified between playfulness and creativity (Pearson's $r=.727$ ). The optimism, playfulness, and creativity of new immigrant schoolchildren in Tainan were highly significantly positively correlated; the hypotheses of the study were supported.

Table 1. Two-way ANOVA to assess the interrelationship of optimism and playfulness on creativity.

\begin{tabular}{cccc}
\hline \multirow{2}{*}{ Dimension } & \multicolumn{2}{c}{ Creativity } & Note \\
\cline { 2 - 4 } Category & F value & $p$ value & \\
\hline Optimism & 2.842 & $.000^{\star * *}$ & High $>$ Low \\
Playfulness & 9.799 & $.000^{\star * *}$ & High $>$ Low \\
Optimism & 3.430 & $.000^{\star * *}$ & \\
\hline
\end{tabular}

${ }^{*}{ }^{* *}$, and ${ }^{* *}$ denote $p<.05$ (statistically significant), $p<.01$ (statistically very significant), and $p<.001$ (statistically highly significant), respectively.

Table 2. Analysis of correlation between research variables.

\begin{tabular}{ccccccc}
\hline \multirow{2}{*}{ Variables } & \multicolumn{2}{c}{ Optimism } & \multicolumn{2}{c}{ Playfulness } & \multicolumn{2}{c}{ Creativity } \\
\cline { 2 - 6 } & Pearson & $p$ & Pearson & $p$ & Pearson & $p$ \\
\hline Optimism & 1 & & & & & \\
Playfulness & .399 & $.000^{* * *}$ & 1 & & & \\
Creativity & .452 & $.000^{* * *}$ & .727 & $.000^{* * *}$ & 1 & \\
\hline
\end{tabular}

Table 3. Analysis of correlation between dimensions of optimism and playfulness.

\begin{tabular}{cccccccc}
\hline \multirow{2}{*}{ Variables \& dimensions } & \multicolumn{5}{c}{ Playfulness } \\
\cline { 3 - 8 } & \multicolumn{2}{c}{$\begin{array}{c}\text { Curiosity } \\
\text { \& spontaneity }\end{array}$} & $\begin{array}{c}\text { Pleasure } \\
\text { in interaction }\end{array}$ & $\begin{array}{l}\text { Concentration } \\
\text { \& involvement }\end{array}$ \\
\cline { 3 - 8 } & Optimistic attitude & .223 & $.000^{* * *}$ & .490 & $.000^{* * *}$ & .220 & $.000^{* * *}$ \\
\hline \multirow{2}{*}{ Optimism } & Pearson & $p$ & Pearson & $p$ & Pearson & $p$ \\
& Optimistic thought & .203 & $.008^{* *}$ & .217 & $.000^{* * *}$ & .277 & $.000^{* * *}$ \\
\hline
\end{tabular}


Table 4. Analysis of correlation between dimensions of optimism and creativity.

\begin{tabular}{llcccc}
\hline \multirow{2}{*}{ Variables \& dimensions } & \multicolumn{4}{c}{ Creativity } \\
\cline { 3 - 6 } & & \multicolumn{2}{c}{ Creative ability } & \multicolumn{2}{c}{ Creative tendency } \\
\cline { 3 - 6 } & Pearson & $p$ & Pearson & $p$ \\
\hline \multirow{2}{*}{ Optimism } & Optimistic attitude & .501 & $.000^{* * *}$ & .468 & $.000^{* * *}$ \\
\cline { 2 - 6 } & Optimistic thought & .198 & $.006^{* *}$ & .184 & $.049^{*}$ \\
\hline
\end{tabular}

Table 5. Analysis of correlation between dimensions of playfulness and creativity.

\begin{tabular}{|c|c|c|c|c|c|}
\hline \multirow{3}{*}{\multicolumn{2}{|c|}{ Variables \& dimensions }} & \multicolumn{4}{|c|}{ Creativity } \\
\hline & & \multicolumn{2}{|c|}{ Creative ability } & \multicolumn{2}{|c|}{ Creative tendency } \\
\hline & & Pearson's $r$ & $p$ value & Pearson's $r$ & $p$ value \\
\hline \multirow{3}{*}{ Playfulness } & Curiosity \& spontaneity & .428 & $.000^{* * *}$ & .469 & $.000^{* * *}$ \\
\hline & Pleasure in interaction & .660 & $000^{* * *}$ & .666 & $.000^{* * *}$ \\
\hline & Concentration \& involvement & .379 & $.000^{* * *}$ & .413 & $.000^{* * *}$ \\
\hline
\end{tabular}

${ }^{*}, * *$ and ${ }^{* * *}$ denote $p<.05$ (significant), $p<.01$ (very significant), and $p<.001$ (highly significant), respectively.

\subsection{Regression Analysis and Moderating Effect Test}

Correlation analysis yielded positive correlations between the variables. We then evaluated the influence of each variable.

\subsubsection{Regression Analysis of Optimism and Playfulness on Creativity}

Tables 6-8 present the regression analysis results. Optimism exerted a highly significant positive effect on creativity, as indicated by the regression coefficient $(\mathrm{B}=.869 ; p<.001)$, and playfulness exerted a highly significant positive effect on creativity, as indicated by the regression coefficient $(\mathrm{B}=.790 ; p<.001)$. Playfulness made the largest contribution to creativity and displayed a significant predictive power (Adjusted $\mathrm{R}^{2}=52.8 \%$; $p<.001$ ); optimism made a slightly smaller contribution, but its predictive power was still significant (Adjusted $\mathrm{R}^{2}=20.3 \%$; $p<.001)$.

Both optimism and playfulness significantly positively affected creativity. As Table 8 indicates, when both are present, the predictive power is improved (Adjusted $\mathrm{R}^{2}=55.9 \% ; p<.001$ ).

We discovered that among immigrant elementary schoolchildren in Tainan, those with higher perceived optimism and playfulness reported a higher level of creativity. Regression analysis also revealed that playfulness moderated the relationship between optimism and creativity; the hypothesis concerning the effect of playfulness was supported.

\subsubsection{Moderating Effect of Playfulness on the Relationship between Optimism and Creativity}

We performed multiple regression analysis to verify the moderating effect of playfulness. We detected a significant effect of the cross-product of the independent 
Table 6. Regression analysis of optimism and creativity.

\begin{tabular}{|c|c|c|c|}
\hline Dependent variable & & Creativity & \\
\hline Independent variable & B & & VIF \\
\hline Constant term & 1.334 & & \\
\hline Optimism & $.869^{* * *}$ & & 1.000 \\
\hline $\mathrm{R}$ & & .452 & \\
\hline $\mathrm{R}^{2}$ & & .205 & \\
\hline Adjusted $\mathrm{R}^{2}$ & & .203 & \\
\hline F value & & 122.280 & \\
\hline$p$ value & & $.000^{* * *}$ & \\
\hline
\end{tabular}

Table 7. Regression analysis of playfulness and creativity.

\begin{tabular}{|c|c|c|c|}
\hline Dependent variable & & Creativity & \\
\hline Independent variable & B & & VIF \\
\hline Constant term & .890 & & \\
\hline Playfulness & $.790^{\star * *}$ & & 1.000 \\
\hline $\mathrm{R}$ & & .727 & \\
\hline $\mathrm{R}^{2}$ & & .529 & \\
\hline Adjusted $\mathrm{R}^{2}$ & & .528 & \\
\hline F value & & 526.603 & \\
\hline$p$ value & & $.000^{\star * *}$ & \\
\hline
\end{tabular}

Table 8. Regression analysis of optimism, playfulness, and creativity.

\begin{tabular}{ccc}
\hline Dependent variable & \multicolumn{2}{c}{ Creativity $(\mathrm{n}=483)$} \\
\cline { 2 - 3 } Independent variable & $\mathrm{B}$ & VIF \\
\hline Constant term & .230 & 1.188 \\
Optimism & $.288^{* * *}$ & 1.188 \\
Playfulness & $.703^{* * *}$ & \\
$\mathrm{R}$ & & .749 \\
$\mathrm{R}^{2}$ & .561 & \\
Adjusted $\mathrm{R}^{2}$ & .559 \\
F value & 526.603 \\
$p$ value & $.000^{* * *}$ \\
*,**, and ${ }^{* * *}$ denote $p<.05$ (significant), $p<.01$ (very significant), and $p<.001$ (highly significant), respectively.
\end{tabular}

variable and moderator on the dependent variable and standardized the variables to overcome the collinearity problem.

In model 1, the effect of " $\mathrm{z}$-score of optimism" on creativity was observed to be significant. In model 2, "z-score of playfulness" was added, in addition to "z-score of optimism." A comparison of the models revealed that "z-score of playfulness" also exerted a significant effect on creativity. Furthermore, the effect of "z-score of optimism" on creativity increased by $30.8 \%$ due to the addition of "z-score of playfulness," confirming " $\mathrm{z}$-score of playfulness" as a crucial mod- 
erator of the relationship between " $\mathrm{z}$-score of optimism" and creativity. In model 3 , we added " $z$-score of optimism $\times z$-score of playfulness" as the moderator in addition to " $\mathrm{z}$-score of optimism" and " $\mathrm{z}$-score of playfulness." A comparison of the models 3 and 2 revealed that " $z$-score of optimism $\times z$-score of playfulness" significantly affected creativity. The predictive power of "z-score optimism" on creativity improved due to the addition of playfulness $(p<.001)$. This suggests that playfulness moderated the relationship between optimism and creativity.

More optimistic respondents reported more creative behaviors. The positive influence of schoolchildren's optimism on creativity can be enhanced by the moderating effect of playfulness. Schoolchildren with higher perceived optimism were more likely to report creative behaviors $(\mathrm{B}=.682, p<.001)$, and the predictive power of creativity was enhanced $(\mathrm{B}=.472, p<.001)$. The increased $\Delta \mathrm{R}^{2}$ confirmed that playfulness moderated the predictive power of optimism on creativity; $\mathrm{H} 3$ was supported (Table 9).

\section{Discussion}

An optimistic attitude was significantly positively correlated with creative ability and creative tendency $(p=.000)$. Optimistic thought was significantly correlated with creative ability $(p=.006)$ and creative tendency $(p=.049)$. This implied that for upper grade new immigrant elementary schoolchildren in Tainan, high levels of optimistic attitude and thought entailed increased creative ability and tendency. This not only supports the research hypothesis regarding correlation but also concurs with the findings of Amabile (1988), Chang and Farrehi (2001), and Luthans et al. (2007).

We also explored the correlation between playfulness and creativity (Pearson's

Table 9. Moderating effect of each variable on creativity.

\begin{tabular}{cccc}
\hline \multirow{2}{*}{ Dependent variable } & \multicolumn{3}{c}{ Creativity } \\
\cline { 2 - 4 } Independent variable & Model 1 & Model 2 & Model 3 \\
\cline { 2 - 4 } Constant term & $\mathrm{B}$ & $\mathrm{B}$ & \\
\hline Z-score of optimism & 1.357 & 2.643 & .241 \\
Z-score of playfulness & .682 & .288 & .016 \\
$\mathrm{R}$ & & .427 & .533 \\
$\mathrm{R}^{2}$ & & & .263 \\
Z-score of optimism $\times$ Z-score of playfulness & .450 & .749 & .979 \\
Adjusted $\mathrm{R}^{2}$ & .202 & .561 & .958 \\
$\Delta \mathrm{R}^{2}$ & .201 & .559 & .957 \\
F value & & $.308^{\mathrm{a}}$ & $.398^{\mathrm{b}}$ \\
$p$ value & 118.639 & 381.708 & 4377.066 \\
\hline
\end{tabular}

${ }^{*}, * *$, and ${ }^{* *}$ denote $p<.05$ (significant), $p<.01$ (very significant), and $p<.001$ (highly significant), respectively. Note: ${ }^{\mathrm{a}}$ and ${ }^{\mathrm{b}}$ respectively denote model 2 -model 1 and model 3 -model 2. 
$r=.727)$ and discovered that respondents with high levels of perceived playfulness were more likely to perceive creativity. Dimension test results revealed that high optimistic attitude and thought-dimensions of optimism-were correlated with dimensions of playfulness (i.e., curiosity \& spontaneity, pleasure in interaction, and concentration \& involvement); the research hypothesis concerning the correlation was supported. Regarding correlations between dimensions of playfulness and creativity, the highest correlation was identified between pleasure in interaction and creative tendency (Pearson's $r=.660$ ). High levels of perceived playfulness increased the likelihood of perceiving various dimensions of individual creativity; this not only supports the research hypothesis regarding correlation but also concurs with findings by Barnett (1991), Glynn and Webster (1992), and Dansky (1999).

The independent variable (optimism) and the moderator (playfulness) were first converted into standard scores (z-scores). The standardized independent variable (optimism) and the moderator (playfulness) were multiplied to assess the moderating effect of playfulness on the relationship between optimism and creativity. Respondents who were more optimistic reported more creative behaviors. That is, the independent variable (optimism) positively predicted the dependent variable (creativity), and the predictive power was increased through the moderating effect of playfulness. High levels of perceived optimism entailed perceived creativity. High levels of perceived playfulness were associated with more creative behaviors and enhanced the predictive power of creativity. The increased $\Delta \mathrm{R}^{2}$ confirmed that playfulness moderated the predictive power of the independent variable (optimism) on the dependent variable (creativity). This result concurs with the findings of a study by Amabile (1988).

\section{Conclusion}

This study explored the optimism and creativity of fifth- and sixth-grade new immigrant children in elementary schools in Tainan as well as measured the moderating effect of playfulness on the relationship between optimism and creativity. Based on the quantitative data collected by questionnaire, we drew the following conclusions.

\subsection{A Significant Positive Correlation Existed between the Optimism and Creativity of the New Immigrant Schoolchildren}

Schoolchildren who were more optimistic (with optimistic attitude and thought) reported higher creativity (creative ability and tendency); accordingly, H1 was supported.

\subsection{A Significant Positive Correlation Existed between the Playfulness and Creativity of the Schoolchildren}

High levels of perceived optimistic attitude and optimistic thoughts-dimensions 
of optimism-entailed higher scores for dimensions of playfulness (i.e., curiosity \& spontaneity, pleasure in interaction, and concentration \& involvement). In the analysis of correlations between dimensions of playfulness and creativity, the strongest correlation was identified between pleasure in interaction and creative tendency. High levels of perceived playfulness increased the likelihood of various dimensions of perceived individual creativity.

\subsection{Playfulness Moderated the Relationship between Optimism and Creativity}

More optimistic students reported more creative behaviors. Optimism positively predicted creativity, and the predictive power was increased through the moderating effect of playfulness. High levels of perceived optimism entailed greater creativity. High levels of perceived playfulness were associated with more creative behaviors while enhancing the predictive power of creativity. That is, playfulness moderated the predictive power of the independent variable (optimism) on the dependent variable (creativity).

Marriages across countries include Taiwan, and their influence on Taiwan's society should not be underestimated. Again, new immigrants account for more than $3 \%$ of Taiwan's population. New immigrants now constitute $9.37 \%$ of elementary school children nationwide, and their needs require greater attention. The present study aimed to attach importance to cultivating the creativity of new immigrant schoolchildren, and its findings may serve as references for researchers, education administrators, and elementary schools.

\section{Conflicts of Interest}

The author declares no conflicts of interest regarding the publication of this paper.

\section{References}

Aguilar, T. E. (1985). Social References and Environmental Barriers to Playfulness. In J. L. Frost, \& S. Sunderlin (Eds.), When Children Play (pp. 73-76). Wheaton, MD: Association for Childhood Education International.

Amabile, T. M. (1983). The Social Psychology of Creativity. Berlin: Springer-Verlag. https://doi.org/10.1007/978-1-4612-5533-8

Amabile, T. M. (1988). A Model of Creativity and Innovation in Organizations. Research in Organizational Behavior, 10, 123-167.

Amabile, T. M. (1996). Creativity in Context. Boulder, CO: Westview Press.

Bandura, A. (1986). The Explanatory and Predictive Scope of Self-Efficacy Theory. Journal of Clinical and Social Psychology, 4, 359-373.

https://doi.org/10.1521/jscp.1986.4.3.359

Barnett, L. A. (1991). The Playful Child: Measurement of a Disposition to Play. Play and Culture, 4, 51-74.

Barnett, L. A. (2007). The Nature of Playfulness in Young Adults. Personality and Individual Differences, 43, 949-958. https://doi.org/10.1016/j.paid.2007.02.018 
Carver, C. S., \& Scheier, M. (2003). Optimism. In S. J. Lopez, \& C. R. Snyder (Eds.), Positive Psychological Assessment-A Handbook of Models and Measures (pp. 75-89). Washington DC: American Psychology Association. https://doi.org/10.1037/10612-005

Chang, E. C., \& Farrehi, A. S. (2001). Optimism/Pessimism and Information-Processing Styles: Can Their Influences Be Distinguished in Predicting Psychological Adjustment. Personality and Individual Differences, 31, 555-562. https://doi.org/10.1016/S0191-8869(00)00159-8

Chang, S. H. (2007). Creativity: Theory, Skills, and Education. Taipei: Wu-Nan Book Inc.

Chen, L. A. (2008). Theory and Practice of Creative Thinking Instruction (Simplified Edition). Taipei: Psychological Publishing.

Cheng, Y. C., \& Tsai, Y. J. (2012). A Study of Relationship among Elementary School Principals' Curriculum Leadership, Teachers' Teaching Belief, Teachers' Innovation Teaching Behavior and Elementary School Students' Creativity Tendency. School Administration Bimonthly, 78, 183-199.

Chuang, M. L. (2012). Research on Creative Thinking Curriculum and E-Learning. Journal of Cheng Shiu University, 2, 163-182.

Csikszentmihalyi, M. (1975). Beyond Boredom and Anxiety. San Francisco, CA: Jossey-Bass.

Csikszentmihalyi, M. (1990). Flow: The Psychology of Optimal Experience. New York: Harper \& Row.

Csikszentmihalyi, M. (1996). Creativity: Flow and the Psychology of Discovery and Invention. New York: Harper Collins.

Csikszentmihalyi, M. (1999). Implications of a Systems Perspective for the Study of Creativity. In R. J. Sternberg (Ed.), Handbook of Creativity (pp. 313-338). Cambridge: Cambridge University Press. https://doi.org/10.1017/CBO9780511807916.018

Dansky, J. L. (1999). Play. In M. A. Runco, \& S. R. Pritzker (Eds.), Encyclopedia of Creativity II (pp. 393-408). San Diego, CA: Academic Press.

Dember, W., Martin, S., Hummer, M., Howe, S., \& Melton, R. (1989). The Measurement of Optimism and Pessimism. Current Psychology: Research \& Reviews, 8, 102-119. https://doi.org/10.1007/BF02686675

Glynn, M. A., \& Webster, J. (1992). The Adult Playfulness Scale: An Initial Assessment. Psychological Reports, 71, 83-103. https://doi.org/10.2466/pr0.1992.71.1.83

Guilford, J. P. (1965). Fundamental Statistics in Psychology and Education. New York: McGraw-Hill.

Hunter, S. T., Bedell, K. E., \& Mumford, M. D. (2007). Climate for Creativity: A Quantitative Review. Creativity Research Journal, 19, 69-90. https://doi.org/10.1080/10400410709336883

Lieberman, J. N. (1965). Playfulness and Divergent Thinking: Investigation of Their Relationship at the Kindergarten Level. The Journal of Genetic Psychology, 107, 219-224. https://doi.org/10.1080/00221325.1965.10533661

Lin, H. S. (2012). The Effect of Mind Mapping Teaching on the Fifth-Grade Students' Creativity and Language Learning Attitude in Elementary School. Forum of Education Research, 4, 219-251.

Lin, X. T., \& Wang, M. R. (1994). Creativity Assessment Packet. Taipei: Psychological Publishing.

Lo, F. C. (2012). Research on Creative Teaching of Chinese Language on the Education Cloud System. Collection of Essays for the Literature and Information Seminar, 6, 
65-82.

Luthans, F., Youssef, C. M., \& Avolio, B. J. (2007). Psychological Capital. Oxford: Oxford University Press. https://doi.org/10.1037/t06483-000

Marzano, R. J. (2007). A Handbook for Classroom Management That Works (Lai, L.C., Trans.). Taipei: Psychological Publishing (Original Work Published 2005).

Oldham, G. R., \& Cummings, A. (1996). Employee Creativity: Personal and Contextual Factors at Work. Academy of Management Journal, 39, 607-634.

https://doi.org/10.5465/256657

Peterson, C., \& DeAvila, M. (1995). Optimistic Explanatory Style and the Perception of Health Problems. Journal of Clinical Psychology, 51, 128-132. https://doi.org/10.1002/1097-4679(199501)51:1<128::AID-JCLP2270510120>3.0.CO;2$\underline{1}$

Runco, M. A. (2007). Creativity Theories and Themes: Research, Development, and Practice. Burlington, MA: Elsevier Academic Press.

Scheier, M. F., \& Carver, C. S. (1985). Optimism, Coping, and Health: Assessment and Implications of Generalized Outcome Expectancies. Health Psychology, 4, 219-247. https://doi.org/10.1037/0278-6133.4.3.219

Scheier, M. F., \& Carver, C. S. (2003). Optimism, Pessimism and Self-Regulation. In E. C. Chang (Ed.), Optimism and Pessimism: Implications for Theory, Research, and Practice (pp. 31-51). Washington DC: American Psychology Association.

Schwarzer, R. (1994). Optimism, Vulnerability, and Self-Beliefs as Health-Related Cognitions: A Systematic Overview. Psychology \& Health, 9, 161-180. https://doi.org/10.1080/08870449408407475

Seligman, M. E. P. (1991). Learned Optimism: How to Change Your Mind and Your Life. New York: Pocket Books.

Shen, T. L. (2005) Creative Principles and Design. Taipei: Wu-Nan Book Inc.

Siau, K. L. (1995). Group Creativity and Technology. Journal of Creative Behavior, 19, 201-216. https://doi.org/10.1002/j.2162-6057.1995.tb00749.x

Simonton, D. K. (1988). Scientific Genius: A Psychology of Science. Cambridge: Cambridge University Press.

Simonton, D. K. (2009). Historiometry in Personality and Social Psychology. Social and Personality Psychology Compass, 3, 49-63. https://doi.org/10.1111/j.1751-9004.2008.00159.x

Snyder, C. R. (2002). Hope Theory: Rainbows in the Mind. Psychological Inquiry, 13, 249-275. https://doi.org/10.1207/S15327965PLI1304_01

Sternberg, R. J. (1988). A Three-Facet Model of Creativity. In R. J. Sternberg (Ed.), The Nature of Creativity (pp. 125-147). New York: Cambridge University Press.

Sternberg, R. J. (2001). What Is the Common Thread of Creativity: It's Dialectical Relation to Intelligence and Wisdom. American Psychologist, 56, 360-362.

https://doi.org/10.1037/0003-066X.56.4.360

Sternberg, R. J. (2003). Creative Thinking in the Classroom. Scandinavian Journal of Educational Research, 47, 325-338. https://doi.org/10.1080/00313830308595

Sternberg, R. J., \& Lubart, T. I. (1995). Defying the Crowd: Cultivating Creativity in a Culture of Conformity. New York: Free Press.

Taylor, S. E., \& Armor, D. A. (1996). Positive Illusions and Coping with Adversity. Journal of Personality, 64, 873-898. https://doi.org/10.1111/j.1467-6494.1996.tb00947.x

Webster, J. (1989). Playfulness and Computers at Work. Unpublished Doctoral Disserta- 
tion, New York: New York University.

Williams, F. E. (1972). Encouraging Creative Potential. Educational Technology Publications.

Williams, R. L. (2002). Creative Performance in the Classroom. Inquiry: Critical Thinking across the Disciplines, 22, 7-20. https://doi.org/10.5840/inquiryctnews20022219

Wu, M. L., \& Tu, J. T. (2010). SPSS \& the Application and Analysis of Statistics. Taipei: Wu-Nan Book Inc.

Yu, P. (2005). Facilitating Playfulness at Work. Research in Applied Psychology, 26, 73-94.

Zhou, J., \& George, J. M. (2001). When Job Dissatisfaction Leads to Creativity: Encouraging the Expression of Voice. Academy of Management Journal, 44, 682-696.

https://doi.org/10.2307/3069410 